\title{
Se você viajar pelo mar do Norte, um artigo, sobre Site Specific, um Romance ${ }^{1}$
}

\section{If you travelling to the North Sea, a paper, about Site Specific, a Novel}

\section{Si viajas por el Mar del Norte, un artículo, sobre Site Specific, una Novela}

\author{
iD Renan Augusto Ferreira Bolognin \\ Universidade Federal de São Carlos(UFSCar), São Carlos, São Paulo, Brasil. \\ renanbolognin@hotmail.com
}

Resumo: Site Specific, um Romance, de Fábio Morais (2013), embrenha o texto literário narrativo em artes diversas e em uma monografia acadêmica. Para analisarmos o arranjo estrutural do livro, este artigo o dispõe como palavras convertidas em imagens e toma o texto "Voyage on The Norte Sea", de Rosalind Krauss (1999), como norteador da compreensão dessa obra de literatura que flerta com o audiovisual. Como conclusões, além de notarmos a eficácia estética de um livro escrito que pode ser arte pictórica, aventamos que a obra parece apontar a relação entre humanidade, literatura e imagem como cada dia mais estreita.

Palavras-chave: Site Specific, um Romance. Fábio Morais. Rosalind Krauss.

\begin{abstract}
Site Specific, um Romance, by Fábio Morais (2013), unites the narrative literary text in several arts and in an academic monograph. In order to analyze the structural arrangement of the book, this paper presents it as words converted into images and takes the essay "Voyage
\end{abstract}

1 Este texto é dedicado a todas as famílias que perderam entes queridos e às que têm mantido uma nutrição insuficiente nessa pandemia de covid-19: que ele possa aquecer seus corações. Também não deixo de agradecer à profa. Dra. Florencia Garramuño por me receber gentilmente como seu estudante na disciplina “La vida impropia: figuras de lo impersonal y anónimo en la cultura contemporânea", da qual surgiu parte das reflexões deste texto. 
on The North Sea", by Rosalind Krauss (1999), as a foundation to the understanding of this singular literature work related to audiovisual. Besides noting the aesthetic efficacy of a written book that can be an image art, as conclusions, I suggest that the work seems to point to the relationship between humanity, literature and image as ever closer,.

Keywords: Site Specific, um Romance. Fábio Morais. Rosalind Krauss.

Resumen: Site Specific, um Romance, de Fábio Morais (2013), incrusta el texto literario narrativo en varias artes y en una monografía académica. Para analizar la disposición estructural del libro, este artículo lo presenta como palabras convertidas en imágenes y toma el ensayo "Voyage on The North Sea", de Rosalind Krauss (1999), como cimiento teórico para la comprensión de esta obra literaria relacionada con lo audiovisual. Como conclusiones, además de constatar la eficacia estética de un libro escrito que puede ser arte pictórico, sugerimos que la obra parece señalar que la relación entre humanidad, literatura e imagen será cada vez más estrecha.

Palabras clave: Site Specific, una Novela. Fábio Morais. Rosalind Krauss.

Submetido em 30 de abril de 2020.

Aceito em 06 de julho de 2021.

Publicado em 03 de novembro de 2021. 
Se você viajar pelo mar do Norte, um artigo, sobre Site Specific, um Romance Renan Augusto Ferreira Bolognin

\section{Esboço}

If you travelling to the North country fair (DYLAN, 1963)

Uma capa elaborada por Marcel Broodthaers para uma edição de 1974 da [revista] Studio International, servirá de introdução ao que tenho a dizer aqui. É uma réplica que soletra FINE ARTS (BELAS ARTES) com a imagem de uma águia [Eagle] fornecendo a última letra de "Fine" [Belas] e uma de um burro [Ass] funcionando como a primeira de "Arts" [Artes] ${ }^{2}$ (KRAUSS, 1999, p. 9).

O rascunho é um espaço adequado para velejar o negro da caneta por inúmeras direções, sem nos preocuparmos com as tempestades e correntezas violentas. Todo rascunho começa como papel em branco a ser preenchido e posteriormente rasgado, rasurado e reaproveitado. Se essa breve apresentação sobre a função de um esboço não parece elucidar claramente sua função, talvez seja necessário apresentar como o livro Site Specific, um Romance, de Fábio Morais (2013), é central para iniciar jovens marujos na navegação das águas tumultuosas da literatura que interage com outras artes, principalmente, as visuais. Esse livro, objeto analisado neste artigo, é semelhante àquelas viagens de destino desconhecido nas quais percebemos nossas ignorâncias no final da experiência. Talvez essas viagens sejam as mais deliciosas, pois são nelas que mais aprendemos e nos levantamos de nossas confortáveis poltronas.

No livro de Fábio Morais, a viagem consiste em navegar pelas águas da monografia dissertativa, da arte audiovisual e dos capítulos de um romance. Para isso, cabe mencionar que esse livro singular foi uma dissertação de mestrado defendida pelo autor junto ao Programa de Pós-Graduação em Artes Visuais da Universidade

2 Adicionei todas as palavras entre colchetes para explicar o difícil jogo de linguagem da capa da revista comentada por Rosalind Krauss e o humor ácido dessa obra em relação às belas artes. Essa tradução, assim como outras deste artigo, é nossa. 
Se você viajar pelo mar do Norte, um artigo, sobre Site Specific, um Romance Renan Augusto Ferreira Bolognin

do Estado de Santa Catarina ${ }^{3}$ e orientada pela professora Regina Melim. Essa obra também entranha na escrita romanesca e na investigação científica um trabalho visual, fruto de uma pesquisa bibliográfica profunda (res)significante do olhar de leitor/a à escrita como matéria visual. A participação de leitor/a sobre a matéria escriturária em seu Site Specific, um Romance, ao virar a página do livro, é como o de uma representação pictórica verbalizada: olhar um quadro, caminhar em uma exposição, assistir televisão etc., mas fazendo tudo isso com palavras.

Nesse modo outro de representação verbal, a subjetividade inoculada pelo discurso narrativo se converte em imagem. Por isso, as palavras são organizadas imageticamente. Como se a organização semiológica das palavras do "romance" de Fábio Morais esboroasse a leitura verbal, utilizada há séculos em diversas sociedades ocidentais, em favor de um efeito de uma obra que se desdobra como pintura e exposição. Para exemplificar essa finalidade imagética do romance, basta uma olhadela no trabalho gráfico da capa. Seu design demonstra palavras dobráveis similares à designação "artes plásticas". Em outras palavras, o romance propõe que nos aproximemos do texto por seu caráter visual.

Figura 1: Site specific, um Romance

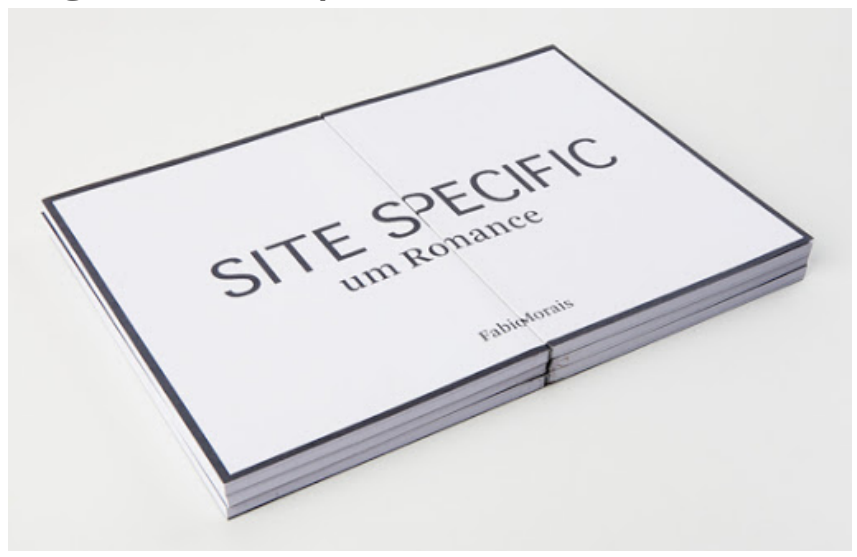

Fonte: Fábio Morais (2013). Par(ent)esis. Disponível em: http://www.plataformaparentesis.com/site/publicacoes/site_specific.php. Acesso em: 10 abr. 2021

3 Cabe informar que essa obra foi defendida no programa mencionado no ano de 2012 e publicada no ano de 2013 pela editora Par(ênt)esis. Curiosamente, no site oficial da instituição não consta a versão digital para download, tampouco alguma informação a esse respeito. Nós a encontramos disponível para download no seguinte endereço (e por tratar-se de obra produzida em um Programa de Pós-Graduação de uma instituição pública, cremos justo divulgá-la): https://docplayer.com.br/18844709-Site-specific-um-romance-fabio-dos-santos-morais.html. Acesso em: 14 abr. 2021. 
Se você viajar pelo mar do Norte, um artigo, sobre Site Specific, um Romance Renan Augusto Ferreira Bolognin

Para analisar o livro, propomos duas seções que equilibram crítica e teoria. Em "Palimpsesto", debatemos como Site Specific, um Romance parece reaproveitar obras anteriores e/ou desveladas na leitura. Demonstramos esse livro como uma coletânea de textos polidos, quase rascunhos de obras de outrem, erigindo nossa fundamentação teórica no livro/artigo "Voyage on the North Sea" de Rosalind Krauss, que também nomeia este texto. Na segunda parte, "Arte final", aproveitamos a obra homônima de Marcel Broodthaers, também analisada por Krauss, como crítica ácida às belas-artes. Similarmente, a de Fábio Morais parece apontar modos outros de escrita de um romance.

\section{Palimpsesto}

O capítulo "Velatura" - o mais longo do livro de Fábio Morais - é premente, segundo informa o atípico editor em nota: "[...] o autor de Site Specific, um Romance diz, na entrevista, que "Velatura" é uma escultura cheia de transparências" (MORAIS, 2013, p. 112). A escrita de Site Specific, um Romance assemelha-se a essa técnica de pintura, que se trata de uma cobertura de tinta com pincel que deixa algumas frestas da camada de tinta usada anteriormente em uma tela. A velatura é similar a um palimpsesto, texto/suporte mise en abyme que contém outros textos inumeráveis debaixo do principal. Decididamente, a obra de Fábio Morais está intrincada na leitura de várias camadas perscrutadas singelamente como uma visualidade de palavras, semelhante a pinturas entrelaçadas.

Em outros termos, na obra de Fábio Morais, contemplamos as palavras pictoricamente e notamos as linhas de um texto literário em suas reentrâncias. Site Specific, um Romance é justamente um texto interseccionado com artes audiovisuais, escultóricas, musicais, pictóricas e gêneros dissertativos. Além dele, outros inúmeros livros teceram relações promíscuas com outras artes e gêneros discursivos. Para isso, podemos recordar um documento oficial do 
Se você viajar pelo mar do Norte, um artigo, sobre Site Specific, um Romance Renan Augusto Ferreira Bolognin

governo nazista em O irmão alemão, de Chico Buarque (2014), que intersecciona o campo da documentação ao literário.

Figura 2: Solicitação de certidão de nascimento de Sergio Buarque e de seus pais para a comprovação da ascendência ariana do pai de Chico Buarque para a finalidade de efetivação do processo de adoção do filho alemão, Sérgio Ernst, por uma família também alemã.

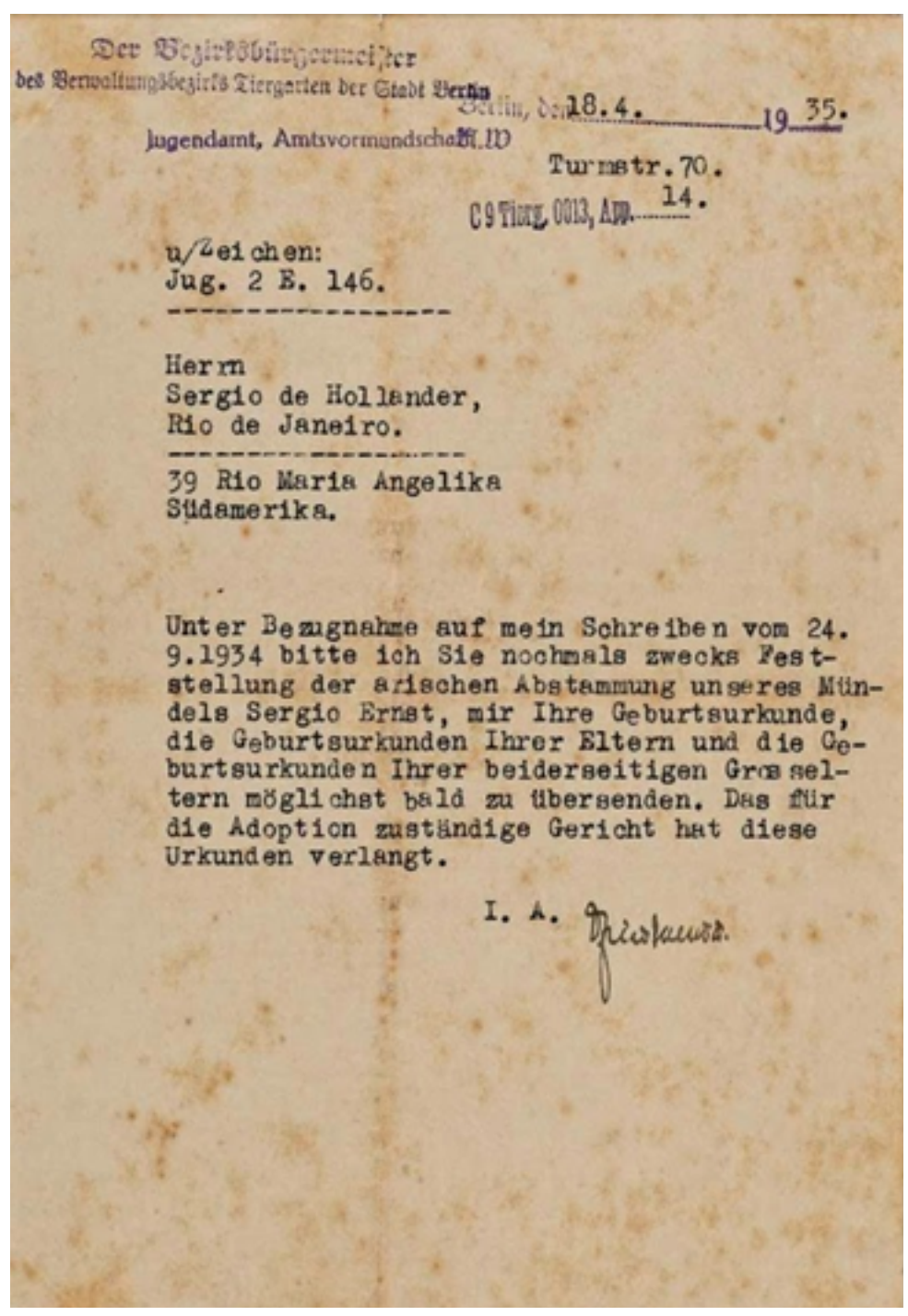

Fonte: Chico Buarque de Holanda (2014, p. 235).

Em El infarto del alma, Diamela Eltit e a fotógrafa Paz Errázuriz interseccionam fotos de internados no manicômio de Putaendo e constituem uma literatura-visual. Em Agua con chocolate, Laura 
Se você viajar pelo mar do Norte, um artigo, sobre Site Specific, um Romance Renan Augusto Ferreira Bolognin

Esquivel desconstrói o olhar do/da leitor/a com um caderno de receitas colocado em um romance. Entre outros textos pictórico-verbais, um poema da venezuelana Emira Rodríguez é o que mais recorda a estética do livro de Fábio Morais:

pondo o papel carbono ao contrário poderá me ler através do espelho há cubos com pictografias um menino com cabeça de pássaro saindo do bosque de Jerônimo buscando uma lanterna e de fósforo se, por acaso, se apague a lanterna assim poderá olhar para trás sem que te digam nada venham, secam-se as pedras negras do quadrante no signo de vênus manuseie-as devagar. há um pôster escrito com tinta indelével que diz: "é azul e tem somente quatro pétalas" mas é verde e tem somente asas transparentes como as moscas dos podredouros celofane com estrias oleandro é o nome de uma flor adiante pescoços corajosos de soldados virgens não digam a ninguém que os estamos desafiando ao silêncio, cada vez que paremos (2008, p. 25, tradução livre nossa) $)^{4}$.

O poema de Emira Rodríguez é representado com uma base pictográfica. Suas imagens poéticas, como a obra inteira da autora, se assemelham a um sistema de escrita de representação imagética. Diferentemente, a autora constitui as imagens de seu texto como desenhos primitivos pintados na parede, feitos com palavras. Igualmente, o livro de Fábio Morais se destaca pictogra-

\footnotetext{
4 "poniendo el papel carbón al revés podrás leerme a través del espejo/ hay cubos decorados con pictografías/ un niño con cabeza de pájaro saliendo del bosque/ de jerónimo busca una linterna y/ fósforos por si se apaga la linterna/ así podrás mirar atrás sin que te digan nada/ vamos se están secando las rocas negras del cuadrante/ en el signo de venus/ manéjalas despacio. hay un cartel escrito con tinta/ indeleble que dice: "es azul y tiene sólo cuatro/ pétalos" pero es verde y tiene sólo alas/ transparentes/ como las moscas de los pudrideros/ celofán con estrías/ adelfa es el nombre de una flor/ jadelante cuellos animosos de soldados vírgenes! / no os lo diga nadie que estamos desafiando/ al silencio cada vez que cesamos".
} 
Se você viajar pelo mar do Norte, um artigo, sobre Site Specific, um Romance Renan Augusto Ferreira Bolognin

ficamente. A estrutura de seu livro se ampara na indecisão e indiscernibilidade de uma forma aglutinadora. Assim, seu romance se assemelha a um gênero planetário, terminologia cunhada por Sandra Guardini Teixeira Vasconcelos (2010) para referir-se à coletânea de Franco Moretti e ao comportamento estrutural do gênero romance nas distintas sociedades ocidentais.

Site specific, um Romance se refere, ironicamente, à forma romanesca consagrada por inúmeras/os autoras/es dando azo à exploração de sua particularidade camaleônica, além de um site specific. Traduzindo a expressão, esse lugar específico é a criação de um ponto de vista artístico, surgido da escrita envolvida com a imagem, e para o qual se deve olhar. Espacialmente, esse lugar específico expõe um público e os lugares de circulação desse texto planetário. Para isso, sigamos com a palavra do atrativo editor do livro: "Site specific, um Romance é também um site specific, muitas vezes intraduzível - e no campo da arte brasileira a produção artística que mais se ajustava à sua [do autor] percepção de literartura" (MORAIS, 2013, p. 117, colchetes nossos).

Portanto, esse livro palimpsesto é um romance coberto por um amontado de pinturas verbais, flertes com obras audiovisuais, frestas expostas e interpretações, anunciando (poética e talvez sarcasticamente) um novo meio artístico: a literartura,

[...] um termo que, mais que querer cunhar, percebo na leitura de vários textos citados na pesquisa - e, a partir dela, produzir a obra literartística Site Specific, um Romance. [...] penso ter insinuado uma definição [...], texto que funde obra prática e dissertação (MORAIS, 2013, p. 119).

O conceito de romance que comungamos - como os inúmeros ensaios do livro de Franco Moretti - possui estruturas consolidadas sócio, histórica e politicamente falando. Igualmente, o campo literário, seus jogos e procedimentos formataram a literatura impositiva e rigidamente. Desse modo, o romance de Fábio Morais ilumina um modo outro de construção romanesca: literartura que 
Se você viajar pelo mar do Norte, um artigo, sobre Site Specific, um Romance Renan Augusto Ferreira Bolognin

requer um campo específico e está localizada na fronteira de artes letradas que tocam as imagéticas. De outro modo, é como se Site Specific, um Romance apagasse suas imagens enquanto se convertesse em narrativa, apagasse sua narrativa enquanto se convertesse em imagem. Como os melhores truques de prestidigitação: seus textos causam a impressão de uma narrativa emperrada, prestes a acontecer e que, talvez, nunca funcionará potencialmente.

Rosalind Krauss (1999) explicita a viagem ao mar do norte - ou a viagem da retina do espectador/leitor ao assistir a obra homônima concebida por Marcel Broodthaers - como uma metáfora do entrelaçamento de campos artísticos que estão além de constatações (quase) estruturais explicitadas no conhecido ensaio da estadunidense sobre os limites da escultura contemporânea de então em relação com a paisagem e a arquitetura ${ }^{5}$.

No prefácio da obra de Krauss, Benjamin Buchloch (1999, p. 7-9, tradução e grifo nossos) explora a especificidade dos meios artísticos como colapsada e corrompida pela ascensão da crítica pós-modernista e seu entroncamento na indústria cultural:

Isto é verdadeiro a nível histórico, pois o destino deste conceito parece pertencer cronologicamente à ascensão de um pós-modernismo crítico (uma crítica institucional, site specificity) que, por sua vez, produziu suas próprias consequências problemáticas (como o fenômeno internacional da arte da instalação). Isto é, parecia que apenas o "meio" enfrentaria esta mudança de eventos. E em um segundo nível lexical), é a palavra "meio" e não algo como "automatismo" que traz a questão da "especificidade" - como na designação "especificidade do meio". [...] Com a clarividência cansativa do materialista, Broodthaers antecipou em meados dos anos 60, a transformação completa da produ-

\footnotetext{
5 Krauss também repercutiu a expansão artística em um artigo publicado por ela em 1979, Sculpture in the expanded field. Além de muito utilizado para abordar a gênese do debate sobre artes expandidas, o artigo foi traduzido no Brasil como "A escultura no campo ampliado" e seus debates sobre a escultura contemporânea de então estar interseccionada com outras estratégias, a paisagem e a arquitetura. Embora de uma maneira quase matemática e estrutural, nesse artigo ela (1979, p. 30, tradução nossa) argumenta que a escultura, ou "[...] [ess]a categoria pode tornar-se quase que infinitamente maleável ([...] the category can be made to become almost infinitely malleable)".
} 
Se você viajar pelo mar do Norte, um artigo, sobre Site Specific, um Romance Renan Augusto Ferreira Bolognin

ção artística em um ramo da indústria cultural, um fenômeno reconhecido só agora6.

O lugar específico (site specificity) está entrelaçado na tradição e/ou na formatação do campo artístico/ou meio que o veicula ou o comunica a leitores e fruidores. A construção textual de Site specific, um Romance não dignifica outros meios menos usuais para a construção de um texto literário, mas utiliza as potencialidades da impressão no papel para colapsar, corromper e deslocar o literário ao umbral das outras artes. Não por acaso, um dos textos contemporâneos mais propalados a respeito das artes posicionadas em limiares é Literaturas pós-autônomas, de Josefina Ludmer (2007). Nele, a autora mergulha teoricamente no envolvimento de uma literatura fictícia imiscuída em comprovações históricas possíveis, (auto)biográficas e documentárias, possivelmente vivenciadas por escritores e escritoras. Essas literaturas pós-autônomas se amparam em uma indecibilidade (se usarmos um conceito derridiano) colorida pelos lápis da realidade e da ficção. De acordo com Ana Maria Amado Continentino (2006, p. 17-18), o raciocínio desses indecidíveis também contamina termos do cotidiano que merecem debates. Evidentemente, no livro de Fábio Morais a indecibilidade apresentada de maneira mais potente é a da hesitação entre obra romanesca e obra pictórica.

No mais, chama a atenção o fato de Ludmer se dedicar à demonstração de como o caráter pós-autônomo da obra de arte contemporânea integra a via estética de uma literatura escrita em um meio específico: o livro. Nessa feita, o termo grifado na citação de Benjamin Buchloch corresponde diretamente não só ao título do livro analisado, como também à expansão literária dentro de seus limites impostos e para além deles. A especificidade dobra$\mathrm{da}$, forjada, refeita, reescrita, ressemantizada, retematizada de Site

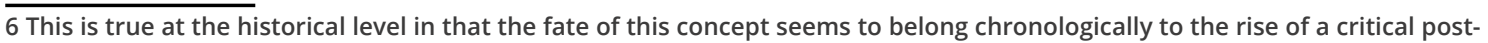
-modernism (institutional critique, site specificity) that in its turn has produced its own problematic aftermath (the international phenomenon of installation art). It seemed, that is, that only "medium" would face onto this turn of events. And at II lexical level), it is the word "medium" and not something like "automatism" that brings the issue of "specificity" in its wake - as in the designation "medium specificity". [...] With the canny clairvoyance of the materialist, Broodthaers anticipated, as early as the mid-1960s, the complete transformation of artistic production into a branch of the culture industry, a phenomenon which we only now recognize. 
Se você viajar pelo mar do Norte, um artigo, sobre Site Specific, um Romance Renan Augusto Ferreira Bolognin

specific, um romance atinge o convencionado como literário devido à especificidade de seu meio e por esse motivo, talvez, seja uma exploração tão visual quanto a corruptela de sua forma.

Essa arte se entronca aos meios da indústria cultural, possivelmente em obras como a de Fábio Morais que não abdicam da participação nos meios livrescos e editoriais. Se notarmos bem a primeira figura deste livro e a associarmos à argumentação de então, notaremos que, embora possua uma estética diferente do ponto de vista romanesco, do ponto de vista editorial ainda se trata de um livro. Segundo Krauss (1999, p. 10), os modernistas já sondavam a essência do que seria a pintura, ou o que a fazia específica como um meio artístico em si. Para isso, a autora menciona que Joseph Kosuth propunha que o colapso provocado pelo hibridismo de inúmeras formas artísticas não fosse abarcado pela redutora palavra "específico", posicionada ao lado de "objetos", mas pelo termo "gerais" para amplificar como um meio é constituído por componentes historicamente sacralizados. Por isso, esse mesmo artista é novamente referido por Krauss com a ardente afirmação: "Ser um artista hoje em dia significa questionar a natureza da arte" (tradução livre nossa)7.

A esse respeito, Krauss (1999, p. 11, grifos da autora) argumenta que,

Os meios específicos - pintura, escultura, desenho - tinham investido suas reivindicações de pureza em ser autônomos, ou seja, em sua declaração de ser nada mais que sua própria essência já que eles eram necessariamente desvinculados de tudo o que estava fora de suas molduras. O paradoxo era que, sua autonomia tinha se mostrado quimérica e os próprios modos de produção da arte abstrata - suas pinturas executadas em série, por exemplo, pareciam carregar a impressão de serem uma commodity produzida industrialmente e internalizando dentro

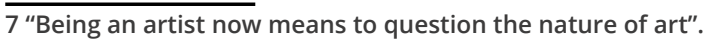


Se você viajar pelo mar do Norte, um artigo, sobre Site Specific, um Romance Renan Augusto Ferreira Bolognin

do campo da obra seu próprio status intercambiável e, portanto, de puro valor de trocå .

O livro de Fábio Morais em pouco se parecerá com uma commodity, pois ele não se trata de um objeto de fruição industrial, mas estético. Seu trabalho estrutural se assenta justamente no abandono da pretensão de uma autonomia artística e de uma hermenêutica dedicada a públicos específicos - como apenas os literatos, pintores e conhecedores profícuos desses campos - que garantirão o escape da obra de diversos circuitos do mercado através do livro (ou do texto literário), distribuído em diversas formas (ou suportes) e sites (ou lugares).

Nesse ponto, nos perguntaríamos se os campos literário, artístico e os demais ainda estão apartados a ponto de serem necessárias tantas intervenções artísticas como as realizadas pelas/ os artistas modernistas. Para isso, é necessário deslocar os componentes dessa questão para o porquê de essas intervenções ainda serem prementes na arte contemporânea e realizadas por artistas como Fábio Morais. Tomando em conta esse combate e as proporções diferenciadas no tempo presente (na contemporaneidade) como um período sócio-histórico também diferenciado, as ingerências realizadas pelo autor em seu Site specific, um romance vão ao encontro da elaboração (ou quem sabe esclarecimento) de um romance não pautado na narração, mas na potencialização da descrição, como elemento organizador de imagens mentais de obras escultóricas, pictóricas, pictográficas etc. representadas nas palavras de um livro. Em outras palavras, Site specific, um romance é um território ainda a ser esquadrinhado, ilustrador do texto imagético da contemporaneidade feito com palavras.

Por isso, nos perguntamos: esse livro seria então uma arte nova? Para responder a essa questão, tão concernente à análise do livro, é cabível tornar nossas as palavras de Ítalo Calvino (1990) so-

8 The specific mediums - painting, sculpture, drawing - had vested their claims to purity in being autonomous, which is to say that in their declaration of being about nothing but their own essence, they were necessarily, disengaged from everything outside their frames. The paradox was that, his autonomy had proved chimerical, and that abstract art's very modes of production - its paintings being executed $\mathrm{m}$ serial runs, for example seemed to carry the imprint of the industrially produced commodity object, internalizing within the field of the work its own status as inter-changeable and thus as pure exchange value. 
Se você viajar pelo mar do Norte, um artigo, sobre Site Specific, um Romance Renan Augusto Ferreira Bolognin

bre as palavras aludirem a imagens desde a Divina comédia até às narrativas fantásticas. De acordo com o escritor italiano, a imagem foi matéria de sua escrita, assim como de inúmeros autores que a tomaram para a escrita imaginativa e a criação de apresentações mentais das histórias lidas. Calvino também se perguntava como essas manifestações cognitivas conviveriam e competiriam com a abundância imagética das culturas desse milênio. $O$ resultado disso parece explicitado no livro de Fábio Morais: as palavras desde sempre foram imagéticas e há séculos convivemos com elas sem enfatizarmos suas propriedades visuais. É difícil afirmar com todas as letras que essa literatura-visual represente uma nova arte. Pelo menos, pode-se afirmar que Site Specific, um Romance consolida a filogênese de um romance pictográfico, assim como o livro de poemas da olvidada Emira Rodríguez.

Retornando ao artigo de Rosalind Krauss (1999), notamos uma semelhança do livro de Fábio Morais com a capa da revista Studio International, de 1974, ilustrada com uma obra de Marcel Broodthaers que epigrafa este artigo. O procedimento do escritor brasileiro não se baseia em um princípio hieroglífico ou de ilustrações que representam letras ou ideias, mas em potencializar o poder pictográfico da letra a ponto de ser vista não como matéria verbal, mas enfatizando as preciosidades artísticas e imagéticas que a compõem. Tomando como nossas as palavras de Krauss (1999, p. 12, tradução livre nossa) sobre a obra de Broodthaers, o mesmo parece se aplicar à obra de Fábio Morais: "[...] o triunfo da águia não é anunciar o fim da arte, mas o encerramento das artes individuais e de seus meios e especificidades. No mais, esse triunfo também decreta a forma que a perda da especificidade tomará" ${ }^{\text {. }}$.

$9[\ldots]$ the triumph of the eagle announce not the end of Art but the termination of the individual arts as medium/specific; and it does so by enacting the form that this loss of specificity will now take. 
Se você viajar pelo mar do Norte, um artigo, sobre Site Specific, um Romance Renan Augusto Ferreira Bolognin

Figura 3: Fine Arts, de Marcel Broodthaers

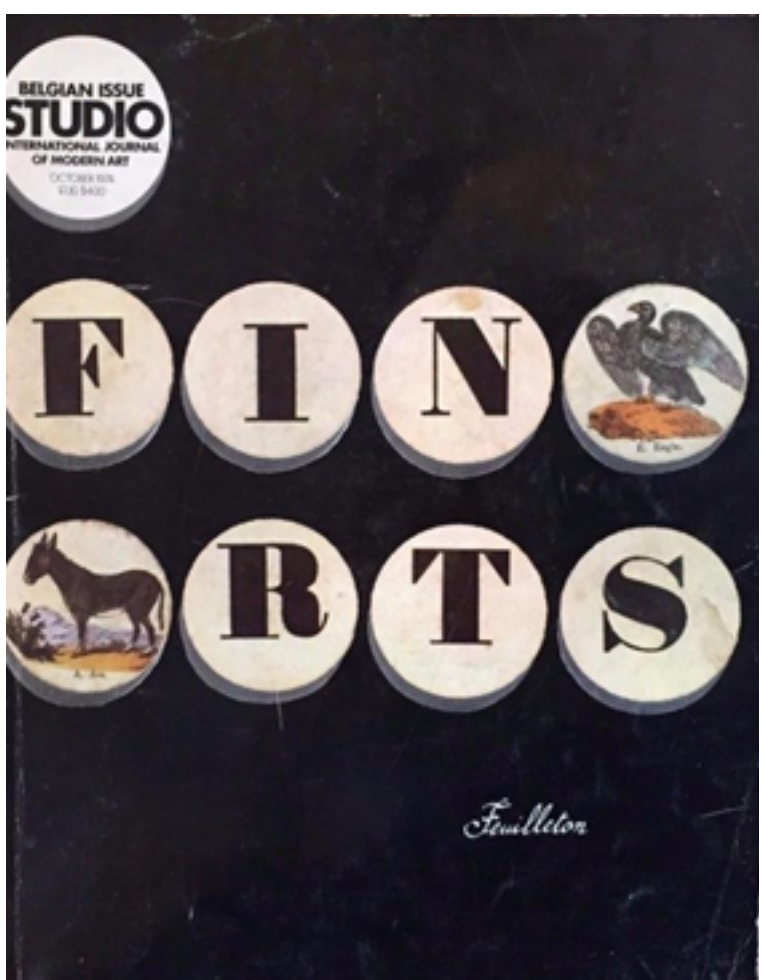

Fonte: Rosalind Krauss (1999, p. 8).

A águia se alia a outras que aparecerão recorrentemente nas obras de Broodthaers. Krauss (1999, p. 20) afirma que essas aves se converterão de símbolo da nobreza, ou das belas-artes, em uma mudança capciosa, constituindo a arte pelo meio material que a estetiza. De acordo com essa figura, haveria um princípio que encontraria sua nascente partindo do chamado readymade (ou já-feitos em tradução literal), conceito duchampiano dadaísta que ampara a construção artística em materiais e objetos previamente existentes na realidade cotidiana. De acordo com o trabalho hermenêutico de Krauss (1999, p. 31-32, tradução nossa), a simbologia da ave ataca diretamente os materiais consolidados como específicos de cada arte. Por isso, "[...] a águia proclama o fim de um meio e de sua especificidade"10.

Ao propor que a arte produzida nos anos de 1960 em diante intensifique $o$ alargamento de suas fronteiras e especificidades, 0

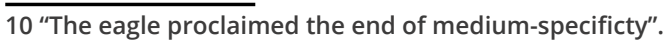


posicionamento da intelectual norte-americana parece endossado pelo modo que o teórico francês Pierre Bourdieu $(1984,1990)$ construiu o conceito de campo. Para Krauss, evidentemente o conceito de especificidade está atrelado ao de meio. Para isso, cabe considerar esses termos materializados no de campo e seus parâmetros sócio-históricos na forma de técnicas e objetos considerados pertencentes a certo campo ou meio.

Bourdieu explorou pela primeira vez o conceito de campo no ensaio "Algumas propriedades dos campos" do livro Questões de sociologia, de 1984. Nesse ensaio, o autor francês explorou o campo como um espaço de posições independentes dos sujeitos. Em outras palavras, os campos possuem leis específicas e mecanismos especializados, embora todos possuam fissuras que podem não ser claras já que suas especificidades podem implicar o reconhecimento de mecanismos aparentemente universais e/ou gêneros comuns a vários deles.

Desse modo, um campo para Bourdieu é reconhecido como um jogo de disputas de posições. Internamente, cada campo propõe um jogo de forças entre pessoas e instituições (1984, p. 120), restringindo e/ou alargando suas especificidades. Nesse ponto, estão localizados choques que balançam e rompem as trancas de um campo ampliado a outros.

Em entrevista de Pierre Bourdieu a Karl Otto Maue, realizada em 1985, o intelectual francês explora especificamente o campo intelectual no capítulo "O campo intelectual: um mundo à parte" da obra Coisas ditas, de 1990. Uma de suas perguntas era questionar se o campo literário e os estudos literários negligenciaram o espaço social. A esse respeito, Bourdieu argumentou que a noção de campo está intrincada ao universo social de maneira particular ao romper referências vagas como contexto, fundo social ou background. Para isso, Bourdieu (1990, p. 169-170) evoca o campo de produção cultural e das letras como meios em que se percebem homologias com outros, como o político e o social. Isto é, entre dominantes e dominados, conservação e vanguarda. O campo transmite os padrões da sociedade em contato com outros dois 
Se você viajar pelo mar do Norte, um artigo, sobre Site Specific, um Romance Renan Augusto Ferreira Bolognin

campos, o político e o social, responsável por consolidar uma percepção sincrônica sobre um determinado campo. Em outras palavras, suas especificidades.

Utilizando de uma base derridiana para uma hermenêutica do período contemporâneo (relativo a 1999 e que Krauss intitula pós-meio), a pesquisadora estadunidense explora como Jacques Derrida revisitou o conceito kantiano de "parergon" e introjetou na sociedade ocidental a planificação de interno e externo. Para a pintura, essa desconstrução passou diretamente pelo deslocamento de sua autonomia enquanto meio e, por suposto, de suas especificidades. Em outras palavras, as artes foram alijadas de suas especificidades e, consequentemente, aproximaram-se de outra maneira de experienciar uma obra de um meio dado (ainda que haja algo remanescente).

De maneira similar, a literatura e suas especificidades se constituíram, autonomizaram e especificaram como um campo e, por isso, produtores e fruidores também foram balançados e dirigidos para a aliança e a aproximação com outros campos das artes, do conhecimento e da ciência. Em outras palavras, se a pintura avançou para além da moldura, a literatura também buscou se enquadrar, retratar e representar-se com especificidades de outros campos. Nas palavras de Krauss (1999, p. 32), isso deslocou “[...] a suposta autonomia da experiência estética, ou da possível pureza de um meio artístico, ou da presumida separação de uma dada disciplina intelectual"11.

O que é posto em questão pelos meios entroncados a outras especificidades parece ser uma experiência de artes entrelaçadas em outras. Os meios artísticos não autônomos das obras de Marcel Broodthaers e de Fábio Morais reescrevem as especificidades dos meios artísticos abordados como um palimpsesto, que, gradual e insistentemente, parece reavaliar o que é literatura, pintura, museu, entre outros meios ou campos e especificidades. Dizendo de outro modo, se a autonomia estética fosse um continente com

$\overline{11 \text { “[...] the supposed }}$ autonomy of the aesthetic experience, or the possible purity of an artistic medium, or the presumed separateness of a given intellectual discipline". 
Se você viajar pelo mar do Norte, um artigo, sobre Site Specific, um Romance Renan Augusto Ferreira Bolognin

algum líquido espesso de pouca mobilidade, Krauss parece indicar que as obras artísticas dos anos 1960 em diante esvaziariam esse meio. Libertariam as artes das couraças que saturam as imaginações mais proeminentes com as quais artistas poderiam se regozijar em produzir e o público em fruir.

Para isso, cabe recordar o primeiro capítulo e o terceiro de Site Specific, um Romance:

Figuras 4 e 5: Ready-made; Espaço expositivo.

REAOY'-MADE ${ }^{3}$

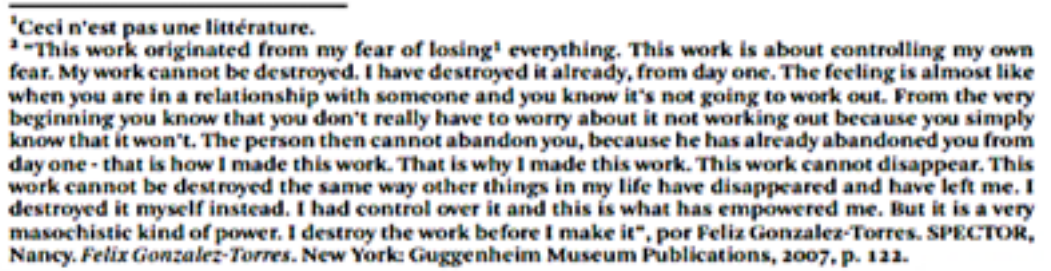

'BtsHog, Elizabeth. New Yotk: Farrat, Straus s Ciroux, Ine, 1983. 
Se você viajar pelo mar do Norte, um artigo, sobre Site Specific, um Romance Renan Augusto Ferreira Bolognin

\section{ESPAÇO EXPOSITIVO}

\section{abcdefghijkl m nopqstuvw xyz}

\section{Fonte: Morais (2013, p. 23); e Morais (2013, p. 17).}

O espaço expositivo da literatura como forma visual, a estética do artista e a argumentação crítica da professora estadunidense contaminam-se como readymades colapsando a diferença, antes quase inexistente entre estética e commodity ${ }^{12}$. Nesse quesito, Josefina Ludmer (2007) é cirúrgica ao postular a segunda de suas teses a respeito da literatura pós-autônoma: “Todo cultural é econômico. Todo econômico é cultural". As letras foram transformadas em imagem, literatura e, ao mesmo tempo, em mercadoria propagandeada. Sua página em branco oculta as possibilidades ilimitadas de escrita e na nota de rodapé se lê uma paródia de Magritte "Isto não é literatura" (Ceci n'est pas une littérature).

Essa obra se empenha justamente nessa fusão de especificidades, como fizeram as artes conceituais, e nos efeitos do capitalismo que parecem ter tomado a nossa face artística. Sejamos otimistas: por um lado, isso talvez indique que ainda há muito

12 Isso fica claro ao nos darmos conta do boom de editoras pelo Brasil, pelo mundo e/ou pelo crescimento exponencial da Amazon e a venda de seu leitor digital. 
Se você viajar pelo mar do Norte, um artigo, sobre Site Specific, um Romance Renan Augusto Ferreira Bolognin

para lutarmos; por outro, que ainda não perdemos nossa face de humanidade.

\section{Arte final}

[...] a obra é sempre mais inteligente do que quem a produz, o que me faz ir mais além e desconfiar que o mundo é que agrega real significado à obra, e aquele agregado pelo autor é apenas a ficção inicial, o "era uma vez..." a ser completado por qualquer um (MORAIS, 2013, p. 106).

Flora Sussekind (2013) utiliza a expressão “Objetos verbais não identificados", de Christophe Hanna, para se referir a uma construção literária similar a uma colagem de vozes. Essas vozes corais constituem o texto literário, outras formas artísticas e elucidam Site specific, um romance como um texto ruidoso e com abundância de imagens.

O livro de Fábio Morais se retesa em várias vozes. Sua edificação atenta para uma problematização da literatura e de suas formas outras perante a academia. Embora o debate do livro não seja uma discussão límpida às/aos não iniciadas/os à literatura contemporânea ou à forma camaleônica do romance, a especificidade do meio literário é posta em evidência na obra e sugere outros significados para o vocábulo artístico. Emulando o voo da águia de Broodthaers, Site Specific, um Romance decola argumentações:

Na perda intermedial de especificidade na qual a água submete as artes individuais, o privilégio do pássaro é espalhado como uma multiplicidade de sites - cada um dele agora denominados "specific" (KRAUSS, 1999, p. 15, tradução e grifo nossos) ${ }^{13}$.

A forma de Site Specific, um Romance erode a constituição de um livro narrativo. Embora não narrativo, ele quer-se descritivo a

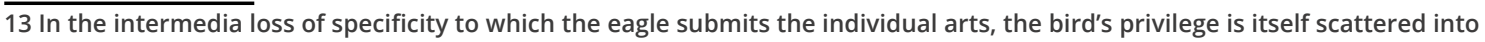
a multiplicity of sites - each of them now termed "specific". 
Se você viajar pelo mar do Norte, um artigo, sobre Site Specific, um Romance Renan Augusto Ferreira Bolognin

ponto de ser considerado pelo editor da obra como um caleidoscópico espiralado análogo a uma obra de Robert Morris (curiosamente comentada pela própria Rosalind Krauss em "Sculpture in the expanded field", de 1979):

\section{Figura 6: Mirrored cubes (Cubos espelhados)}

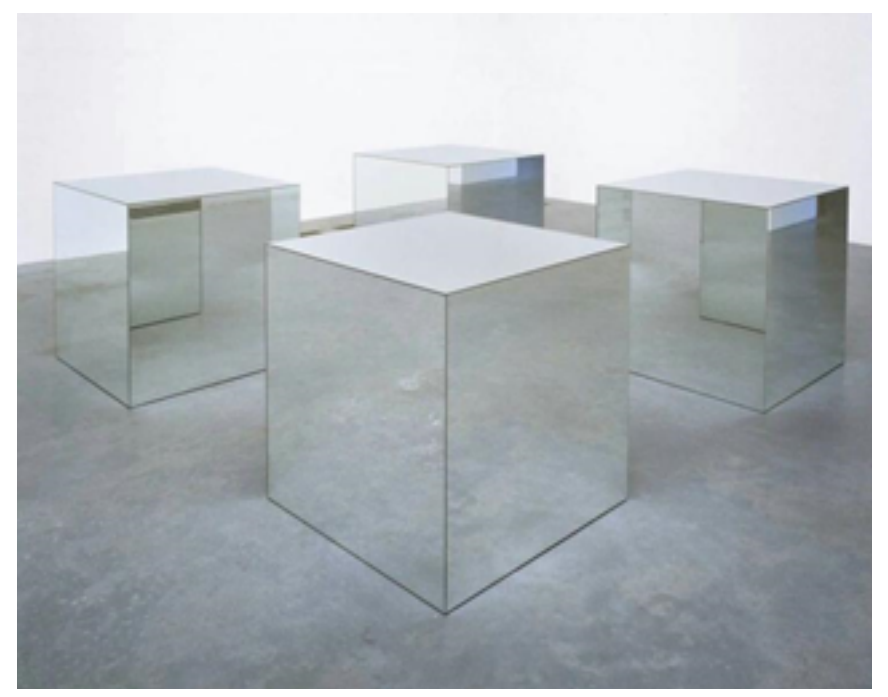

Fonte: Robert Morris (1965).

O desafio em editar Site Specific, um Romance era o fato dele ser um livro cuja natureza fazia com que toda palavra impressa em suas páginas espelhasse o próprio texto. Em uma das muitas discussões de nossa equipe editorial, chegamos a traçar uma analogia entre Site Specific, um Romance, e as salas com cubos espelhados de Robert Morris - talvez o exemplo mais perfeito do que é um site specific - onde não parece haver uma obra, mas núcleos de espelhamento do entorno. Site Specific, um Romance não aparentava existir como romance, mas como uma escrita que se autorrefletia e acabava refletindo quem, e o que, lidava com ela (MORAIS, 2013, p. 97, Grifos do autor).

A estrutura reflexiva da obra de Morris é o parâmetro de um livro que não nomeia o editor da nota sobre o planejamento gráfico da obra. No colofão do livro, a ex-orientadora de Fábio Morais, 
Se você viajar pelo mar do Norte, um artigo, sobre Site Specific, um Romance Renan Augusto Ferreira Bolognin

Regina Melim, é citada como a responsável pela coordenação editorial do livro. No entanto, em nenhum momento do texto a informação sobre a autoria dessa escrita é associada a ela. Inclusive, se acessarmos a gênese do livro como dissertação de mestrado, notaremos que a seção se intitulava "Nota do editor". Nessa versão de texto monográfico, tampouco constava menção à participação da professora como a responsável pela escrita. O procedimento de tornar ambíguo o/a proprietário do texto em questão é um dentre tantos os responsáveis por envergar o texto literário em inúmeros espaços, ou sites, que expulsam os métodos mais comuns dos processos de escritura, edição e relações entre o texto literário, autores, divulgadores e consumidores.

Não por acaso, essa obra de Fábio Morais é um romance constituído por imagens escriturais que podem ser espelhadas e postas lado a lado, tal qual o editor que as intitula, "obras de parede". Nisso, o autor-personagem do livro também é refletido aparentemente ficcionalmente: "Quando decidimos editar o romance, pouco antes da morte do autor, assumi com cuidado essa tarefa" (MORAIS, 2013, p. 97). O autor deveras faleceu?

Essa maneira outra de olhar está amparada no colapso do meio físico livro e desmistifica como ver o literário, a pintura e aponta a desconstrução (ou a necessidade de) de outros modos de fazer: “[...] trata-se de uma obra de literatura ou de artes visuais? Dúvida essa que levava a outra: um texto pode ser lido como obra de arte visual?" (MORAIS, 2013, p. 98). 
Figura 7: Planta baixa.

\section{PLANTA BAIXA}

$N, \operatorname{clr} q n, n t \operatorname{ch}$ fr $d$ md. pns... $s l$, vc lg nmgs ão, ao ue ão, ão e ao oa e oa. Aeas... ei áa, grnds dms. Mstr $\mathbf{n}$ pd ntndr. Qm tm oê eee iïios ae eai. ee ão oia eee. ue e oo ão snhs n pd cmpctr $\mathrm{cm} \mathrm{qm} \mathrm{v} \mathrm{nls} \mathrm{m} \mathrm{mnm}$ d oe oaua o ue ê ee u ío e ioiiiae. á, $a$ i $u$ mpssbldd. $H, h \mathrm{sm} m$ dscmpss, Mstr. dmr ts eoao, ee. Aio eu oo, $u$, oê e ae o uao. ae $s n h s, p t z, v c \mathrm{~nm}$ sb qnto. Tlvz prq $n$ thh oue eu ão ea eu... a... Eu oaa aa o oo aio o $n n h m$... Ms... lhv pr crp frnzn d Mstr, s ee, ua ee oaa e ee e oeio e íuo, oeo o óio mnt Itd $d$ tss cnets $m$ crcl, mrdnd prpr rb, ao, auea aa aa uia, e aaa-o aeuao oee a $\mathrm{i}$ ql brb rl spn, chv- dqd smnt ml nvents oeeo e ciuea. ueia ue oê oe o e Aaie, eu ie cnqnt. Qr q vcfss Frd str, dss bbd Mstr r êao e o ee iu aa eo, e eee. ee ouía u eio úio pr dntr, sm ntndr. Mstr pss $\mathrm{m}$ jt nc $d$ dstrbr e iiui o eo a iuias o uo a aa ooo. Euiiaa uo ps ds njstçs d mnd $\mathbf{n}$ trm ds sss. qulbrv td o eeâia e, uao aaiaa aa eoe o o ão, eiaa ai cm lgne, qnd bxv pr sclhr s LPs n ch, dxv uo, uo, uio, iaa ó o ao a oea. ão ee, ão ou cr td, td, tdnh, fev s slt d cstl. NMstr, $n$ s ooao. Aeas do eo oae e ua ea ieđo. ou aea cnfrmd. pns $n$ tnh vntd $d$ ltr nss drç. $S$ blh oeáia, o, ia ueia aea oao... ee é ia aa a prr, $h$, mnh qrd blh sldd... Mstr vtl pr uaiae. $O$ ia e ue eei io, ue eo e oo eaiaos hmndd. $\mathrm{d} \mathrm{m} \mathrm{q}$ prcbr ss, q $\mathrm{msm} \mathrm{sm} \mathrm{s}$ snhs ou a eouões eias ee é ia aa o uo, ae ee ee e rlzds $s$ rvlçs fts 1 vtl pr mnd, tlvz $1 \mathrm{ntr} \mathrm{m}$ aaóia, oi ee e iíi eee ue e aou a ia uao o ao prn, ps dv sr dfel prebr q s pss vd ltnd pr ioie e, a ua, á ea o oeio ia, á aeaa aa eo a $\lg$ mpssvl, lt, j r bjtv fnl, $\mathrm{j}$ ltrv $\mathrm{pr} \mathrm{mlhr}$ pc oua áea aeáe o uo. ae o ue eu ai aio e oê, r ltrvl d mnd. $S b \quad q \quad m s d m r m v c, M s t r ? .$. ee?... dै? do, ue ieaio o aao... o ue eu ai aio e oê é $H$ ? $N, q$ dlsm crlh... $q \mathrm{~ms}$ dmr $m v \mathrm{~cm}$ oo eoa ão aiee ea é úia.

der t fclmnt ltrs d msc.

A "Planta baixa" se aproxima do desenho de construção civil e arquitetura como especificação física das proporções de um projeto. Nesse primeiro momento, a estrutura do segundo capítulo demonstra a eficácia de uma escrita pictórica-panorâmica que pode incomodar devido à inépcia de a compreendermos como um padrão de leitura diverso. Para isso, cabe notar a estrutura espelhada comprimida nessa escrita de colunas mutuamente complementares, não com a leitura da esquerda para a direita, mas entrelaçando os lados para a formação das palavras. Ou para a 
Se você viajar pelo mar do Norte, um artigo, sobre Site Specific, um Romance Renan Augusto Ferreira Bolognin

compreensão das medidas adequadas de construção de uma literatura conjugada à imagem? A esse respeito, concordamos com o editor da obra:

[...] a definição de literartura nas variadas formas como artistas textaram o texto a partir de parâmetros que escapavam da literatura para se contaminarem pelo vocabulário, pela sintaxe, pelos procedimentos, pelos métodos e pela história de outras artes, como as visuais, o cinema ou a música. Pareceu-nos que, para o autor, seu entendimento de literatura se dava na superação da fronteira entre diferentes linguagens (MORAIS, 2013, p. 99).

A noção de "literartura" amplifica a noção de literatura em relações com outras artes, por sinal, para expandir quais seriam suas especificidades e, obviamente, os modos de leitura possíveis para o objeto literário, ou "literartístico". Os textos desse "romance singular" demonstram a predileção pela inauguração de uma forma diferente daquela que nos acostumamos a chamar de literária ao pôr como relevantes sua materialidade e espacialidade (MORAIS, 2013, p. 104). Por um lado, a experimentação textual dessa "literartura" fricciona a literatura constituída sócio-historicamente, ao longo dos anos, em um caráter letrado; por outro, essa mesma "literartura" também é possível dentro das especificidades e autonomia conquistadas pelo campo das artes visuais (MORAIS, 2013, p. 101). Elaborando de outra forma, o que a viagem verbo-visual do livro parece retratar é antes um avanço dos meios visuais para o literário do que o oposto. Para isso, vejamos o capítulo "Vídeo" na sequência: 
Figura 8: Vídeo.

VIDEO

Em meio á fuga de côres, familiares rejuvenescidos permanecem fixados nas photographias dos annos 1970. Por traz da criança maisvelha, opai de costelletas accende a vela de tres annos. Sua mão está parada no ar emquanto o tom de sua pelle desbota rumo á monochromia magenta. A criança mais nova não está nestas photographias porque o encontro das duas é sómente d'aqui a tres decadas. Além d'isso, o outro garoto nasce seis mezes depois do anniversariante começar a se descolorir n'estas imagens reveladas tres dias apos a festa. Os dois garotos se conhecem na epocha em que as photographias já não são physicas, são códigos: envelhecem por effeitos de photoshop que, artificialmente, antecipam a mesma melancholia magenta dos thios bêbedos que, presos á descoloração analogica, desligam a vitrola laranja e puxam um parabem p'ra você, no anniversario do mais velho. Os dois garotos se conhecem, sessenta annos se passam, e são muitas as imagens dos dois que restam intactas em cantos da internet, HDs, CDs, DVDs, pen drives ou nos depositos onde esse lixo jaz superado. $O$ mais velho está ha dias entubado pela medicina. O mais joven, embora bastante idoso, vai até a distante casa do mais velho para vasculhar albuns antigos, escolhe uma photographia setentista e a leva clandestinamente á UTI. D'esse modo, o môfo vence o codigo e o mais velho consegue morrer.

\section{Fonte: Morais (2013, p. 25)}

A formatação expandida de texto é também perceptível e significada em "Non-Site". Como uma instalação, esse texto enumera alimentos "textuais" como um espaço expositivo. Também permite elucubrar o não lugar e a não especificidade da "literatura". No capítulo homônimo ao título do livro, Site specific, a linguagem verbal se constrói como uma descrição de uma imagem narrativizada e/ou a descrição de inúmeros trechos de um vídeo. O capítulo “Hachura" é construído com uma técnica de pintura de mesmo nome que consiste em pintar/desenhar inúmeras linhas para produzir 
Se você viajar pelo mar do Norte, um artigo, sobre Site Specific, um Romance Renan Augusto Ferreira Bolognin

efeitos, destacar uma região do desenho ou produzir a sensação de textura ao olhar. Trabalho que é instalação artística, texto-instalação.

Figura 9: Non-site

NON-SITE

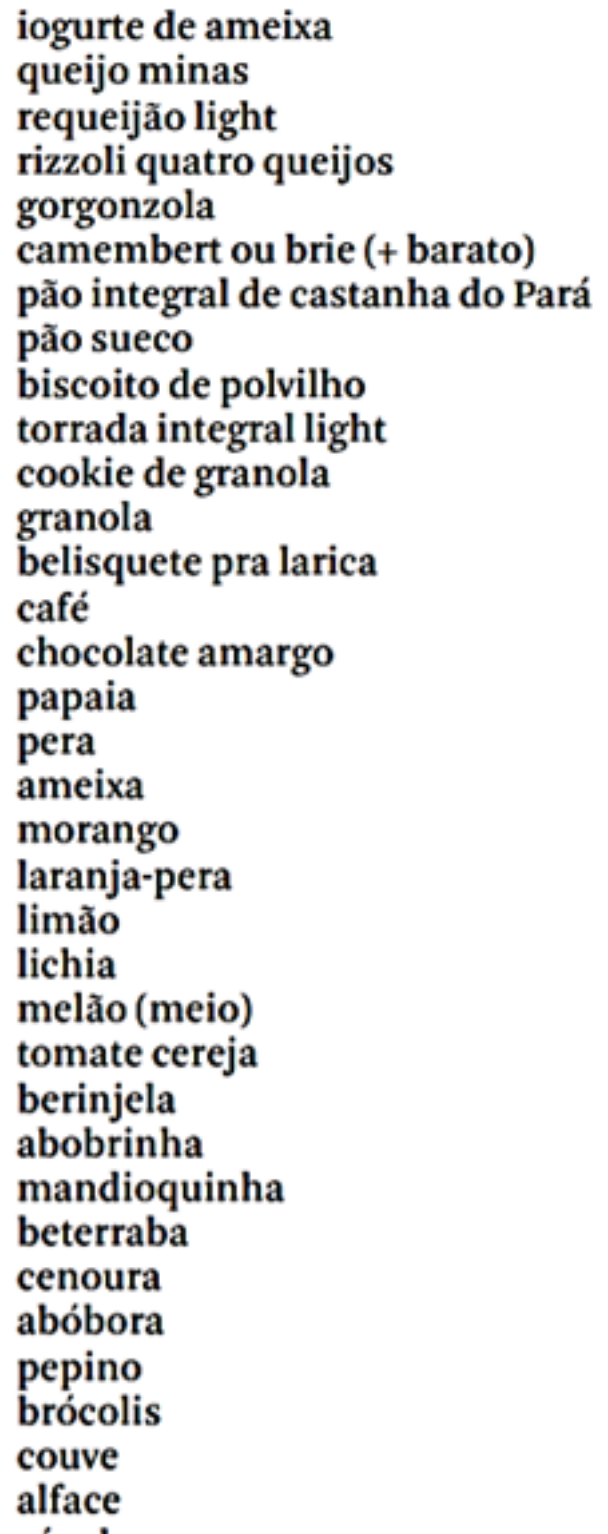


Se você viajar pelo mar do Norte, um artigo, sobre Site Specific, um Romance Renan Augusto Ferreira Bolognin

Figuras 10 e 11: Site Specific; Hachura.

SIrE SPECTIC

e cêt tivesse providenciado socorro e guarda-chuva, ninguém persistiria cuspindo aquela tempestade na cara de ninguém. o resgate teria acontecido sob o toldo e nem precisaria lamber a goteira na têmpora. têmpora tâmara tamarindo taí: tariaí: palavra-bibelô picabiaria rastaquerice. o corpo quente fulminaria a umidade sob o guarda-chuva, a temperatura individual destoaria do redor. cể o pé se afogaria na poça cể a barra do jeans secasse a ferro. cề houvesse tábua de passar, fingiria aquecimento central europeu na cidade tropical. cê sentiria no ar eslovaco? praga, não. o bairro seria toldo inarquitetura. o jeans seria pendurado na parapanturrilha da janela. depois, o fracasso molhado e poluido o forçaria para trás da geladeira. quem resistiria ao desfile sem jeans na cozinha? aguardaria a calça seca e, mesmo que houvesse súplica, não faria traduçào simultânea de en relisant ta lettre do gainsbourg. pra quê? cể entendesse português... seminus são mais burros perto da pia. cế tivesse havido compreensão do que é um erro, fosse ortografia ou indelicadeza, existiria essa instalação d'água na chuva? e cế tivesse comprado camisa com listra vertical, ninguém ficaria disfarçando barriga by bouteille de bière buren. $o$ adiposo teria se escondido atrás da modelagem e nem precisaria fingir gravidez no chalé. chalé chopp chinelo cheuvê: choveríai: feriado chuvoso enchaleraria pas des deux. a toalha mofada azedaria o prazer do banho, o sétimo miojo encruaria a tripa. cê o valete se ofereceria pro rei cê a dama se escondesse na manga. cêt trapaceasse - manual de instruçào, voltaria no último caiaque via rodoviária-enchente. cê arrependeria no primeiro chumaço de serra? chi, nào. treta de viagem nåo surubaria serra. o vai tomar no cêu cu seria escrito com vapor de serraçăo no vidro da poltrona trinta e trềs. depois, o palavrào picharia o box com o hálito do chuveiro. quem corrigiria os erros ortográficos dos desaforos? socaria o pé na porta e, mesmo que xingasse a árvore genealógica, não arremessaria mochila com laptop. pra quê? cê fosse a renata sorrah... possessos quebram coisas antes de liquidarem o carnê. cê tivesse arrancado o coringa, fosse da manga listrada ou de trás do mullet, terminaria sozinho esse fim de feriado? e cê tivesse fofocado no tom certo, ninguém amanheceria encarando personagem de comédia bate-portas. a intriga teria ficado no capítulo de segunda e nem precisaria trazer conflito aqui pra casa. aquipracasa quipracasa quiproquó quiproquo'raí: quiproquo'rariaí: os pensadores explicaria pegapacapá aristotélico. personagem a duelaria donzela do personazem z, zorro falso meteria a colher e o pau. cê o olho roxo se 
Se você viajar pelo mar do Norte, um artigo, sobre Site Specific, um Romance

Renan Augusto Ferreira Bolognin

HACHURA

\begin{abstract}
Ouço Fuga N. 1 do Thiago Pethit e você me chega a essa hora, tenta a chave errada no trinco, ruido de tentativa e erro, teu chaveiro de acrilico no metal do trinco, aclílico, tlinco, aliterando chegada a essa hora?, pô, pra que ligar antes, né?, nem telefona, SMS o escambau, bate a porta, entra, lança no sofá $O$ Paraíso É Bem Bacana que eu te pedi de volta, joga e sobe e voa e erra e cai no chão e rasga a capa que já tá chovida, pô, pra que rasgar capa de livro?, pensa que é cena?, a essa hora de 2012 ainda fingindo cinema?, só porque o ITunes DJ pesca a Anna Karina, Jamais je ne t'ai dit que je t'aimerais toujours, oh mon amour é um perigo, esse violãozinho safado de acampamento a essa hora da noite, madrugad'é emoção fácil e escapismo e lama e PT e a areia do teu All Star arranhando meu chão alugado, você me chega a essa hora, assim, arranhado, pô, me pede pizza e LP, pede pr'eu desligar meu íTunes pra tocar o Macalé, a essa hora?, a sala arranhada e tudo riscado e cê sabe que a vitrola laranja tá com a rotação acelerada um nadinha, cê sabe, pô, por isso a Gal fica com a voz ainda mais fina, cê me chega a essa hora e olha foto por foto do cabelo da Gal na capa do Legal, pô, me presenteia teu perfil distraído analítico e dubla baixo Meu amor me agarra e geme e treme e chora e mata e aponta abraço gay no cabelo da Gal na capa do Legal e erra a letra do Macalé, você me chega assim, a essa hora, lota o ar da casa contigo mesmo, liga a luminária, lança a luz pro alto sem dizer lhufas, dubla o Macalé cada vez mais baixo atévirar só teu pensamento, pô, tá pensando o quê?, esqueceu qu'eu tô aqui?, hein?, a essa hora?, dublando pra dentro?, diz algo, pô, pel'amor, quem chega diz, combinado?, chegada é palavra, palavra é vício ocidental, todo mundo que se encontra só se encontra pra falar, pô, percebeu não?, te obrigo, pô, te peço, te digo, vai, diz algo, porra, silêncio a essa hora?, teu budismo o escambau que você é ocidental pra caralho, Nirvana se matou e passou o pinto na tela da Globo e engasgou o Roberto Marinho, lembra?, a gente era adolescente e vibrou e quis fazer também e pôs o vestido do Kurt e leu uma porrada de livros e depois envelheceu, fala, já que veio pronuncie, ok?, quem mandou?, pô, para de dublar o Macalé pra dentro, canta pra gente, porra, você me chega assim a essa hora, fala pouco e diz nada e quer pizza e mata num só gole meu malbec no gargalo, pô, pede pr'eu telefonar pr'algum disque-qualquer-porra e me pergunta se tem mais vinho, tem, sempre tem, cê sabe que tem, Encuentro argentino, tá em cima da geladeira, vai lá, saca-rolha?, tá'li, pô, pega você, é, o saca-rolha verde e enfia e machuca e esfarela e saca e serve o vinho e brinda teu cono americano no meu de reautiião. vocế me chẹa a essa hora. nô. me nede um nedido
\end{abstract}

Fonte: Morais (2013, p. 31); Fonte: Morais (2013, p. 37).

Essa leitura inespecífica remonta a como arquivos coletados ressoam sentidos sócio-históricos em iminência. De outra maneira, esse conceito de Néstor García Canclini (2016, p. 223) propõe uma arqueologia do futuro que auxilia não somente na compreensão do presente, mas também na predição dos arranjos político, histórico, social, cultural e econômico. Os modos (novos?) de significação do literário em interação com outros campos - como o das monografias de cursos de pós-graduação - demonstram campos incorporando procedimentos relativos a uma possível modificação permanente.

Em encontro com o personagem-autor Fábio Morais, o entrevistador - aparentemente outro alter-ego do pesquisador/artista - constrói as fundações do romance em uma exposição de arte vi- 
Se você viajar pelo mar do Norte, um artigo, sobre Site Specific, um Romance Renan Augusto Ferreira Bolognin

sual que, concomitantemente, desconstrói as diferenças entre autor, personagem, narrador e desestabiliza os liames da realidade:

- Veja aqui na minha cópia. Em Velatura, o jovem pesquisador diz que o velho que lê seu livro na biblioteca afirma desconfiar que ele seja o personagem mais novo. Você acredita que seja ele mesmo? [...]

- Ele é apenas imaginação.

- Somos leitura.

- Personagens?

- Leitura. [...]

Silêncio.

- Eu não era escritor.

- Site Specific, um Romance não é literatura?

- Não. Isto aqui não é uma literatura.

- É o quê?

- Uma exposição de arte visual. Em Site Specific, um Romance eu não tinha que explicar nada. Eu não era escritor. Não tinha que ler manuais de como funciona uma narração. Eu era artista visual, não funcionava por mecanismos literários, não estava contando uma estória. [...] Eu estava somente escrevendo uma escrita. Esculpindo, moldando, editando, deletando, ritmando, velando, colando, elegendo, desenhando, me apropriando (MORAIS, 2013, p. 82-83).

As entrevistas realizadas pelo "suposto" personagem fictício Fábio Morais correspondem à seção que nomearíamos, na maioria das dissertações de mestrado e teses de doutorado, como um capítulo de fundamentação teórica. De modo singular, o último capítulo do livro, Velatura, explora a consecução de sua obra para representar literária, visual e teoricamente a percepção de uma veia de intersecção artística que os mais conservadores de cada um dos campos envolvidos possivelmente considerariam ignóbil. Essa escrita "romanesco-imagética" de Fábio Morais está enganchada no procedimento de pincelar um quadro, uma tela, sinoni- 
micamente ao movimento pictórico da velatura, que nomeia este capítulo do livro, e quer dizer uma mão de tinta aplicada acima de outra que ainda possibilita visualizar a camada de tinta anterior. De certo modo, o capítulo apresenta a magnitude desse romance-monográfico polemizado pelo "personagem" Fábio Morais sobre seu livro ser ou não literário:

- Não. Isto não é uma literatura.

- É o quê?

- Um espaço expositivo.

- Então, o capítulo Velatura é uma pintura, como o título sugere? - Não, Velatura é uma obra literartística. (MORAIS, 2013, p. 84).

Obviamente, a desconstrução dessas linhas romanesco-pictóricas aponta para o procedimento de velamento (ou velatura) do considerado literário, ou não. Em outras palavras, o livro está escondido sobre as pinceladas que cobrem suas narrativas e permite ver, ainda que outra camada de tinta a cubra, a narratividade da obra. A formatação narrativa do último capítulo demonstra esses liames entrelaçados e dificultosamente compreendidos:

Fábio coloca a cópia manuscrita por fim, de Site Specific, um Romance, numa das prateleiras da biblioteca. Ele me acompanha até a saída e, já com a porta aberta, me pergunta se a cópia que Ihe dei foi a manuscrita por mim ou a manuscrita pelo velho da biblioteca. Jogo-lhe um sorriso e digo que a cópia que lhe dei de presente é a que está sendo lida agora (MORAIS, 2013, p. 86).

A espessura das folhas de Site Specific, um Romance é tão fluida que elas parecem inseridas, e não gratuitamente, neste artigo. Este modo de escrita peculiar funde inúmeros textos e desvela modos outros de realização de uma pesquisa acadêmica e posicionamento, ou não, por meio de pronomes pessoais e/ou majestáticos. Funde-se inclusive o/a escritor/a à sua obra e demonstra uma 
Se você viajar pelo mar do Norte, um artigo, sobre Site Specific, um Romance Renan Augusto Ferreira Bolognin

influência central na edificação da obra final a que temos acesso, ainda que a desvele e a ponha quase no anonimato. Essa tendência também é acompanhada no meio acadêmico e na circulação da produção científica, assentada no "entre", ou "[...] entre a literatura e as artes visuais; entre a obra prática e a dissertação sobre seu processo (MORAIS, 2013, p. 105)". Um debate a respeito da interferência do/a pesquisador/a ao relatar os resultados de sua investigação, ainda que utilize das vias da modéstia pronominal, é abordada no livro de metodologia das ciências, Entrenotas, de Cássio Eduardo Viana Hissa (2013), por meio de percepções das produções acadêmicas apontarem a necessidade de novos engenhos e novas artes correspondentes às novas formas de representação artísticas dos/nos tempos atuais. No caso da obra de Broodthaers, ela parece abordar um mundo contemporâneo no qual muitas de suas tecnologias - como a televisão - transformaram-se e mesclaram-se ao texto literário. Em relação à obra de Fábio Morais, esse mundo contemporâneo está cronologicamente próximo ao nosso e, por esse motivo, Site Specific, um Romance possivelmente abre terreno para refletirmos sobre produções artísticas e literárias conjugadas ao boom da imagem digital no tempo presente.

\section{Se você viajasse ao mar do norte, ansiaria relatar o que viu}

Figura 12: A Voyage on the North Sea, de Marcel Broodthaers, 1973.

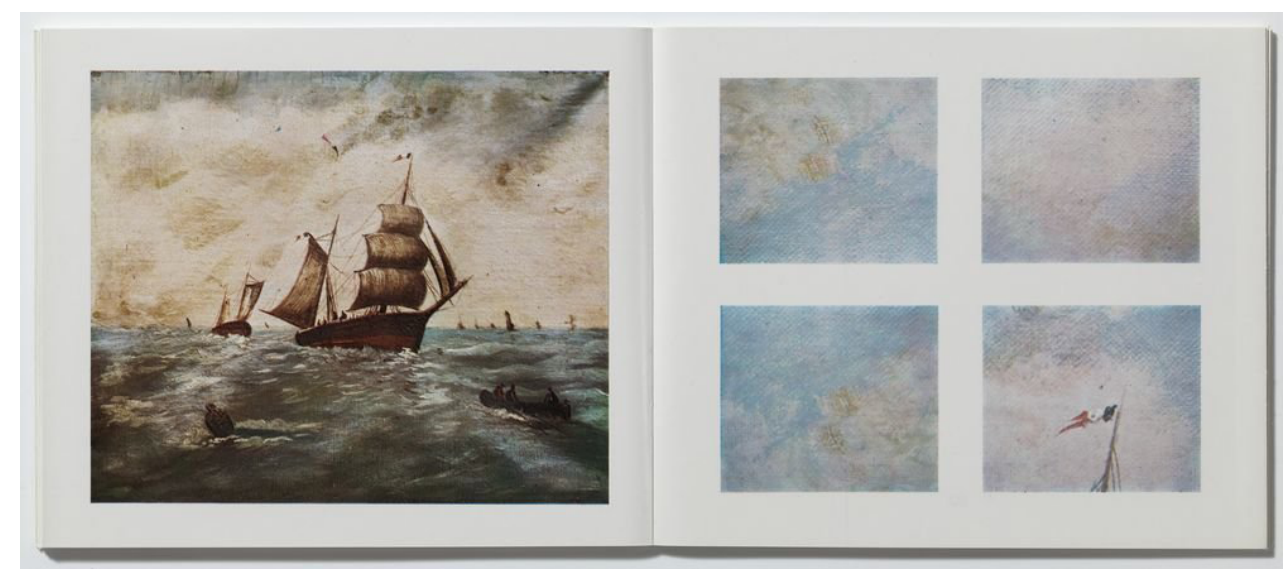

Fonte: Broodthaers (1973). 
O que pode ser vislumbrado na literatura entrelaçada a outros meios, campos, suportes, estratégias e materiais do audiovisual está contido na obra do belga Marcel Broodthaers, $A$ voyage on the North Sea, que nomeou o artigo de Krauss e o nosso. Nessa obra televisivo-literária, o público entrou em contato com uma curiosa e instigante conjugação de vídeo com literatura. Nessa fusão, o artista criou (talvez uma iminência de uma tecnologia similar à dos videogames atuais) uma narrativa curta sobre um navio viajando ao longo do mar do Norte em inúmeros capítulos assistidos e não lidos, como se espera de uma narrativa literária.

A centralidade da obra no livro de Rosalind Krauss, no nosso artigo e no livro de Fábio Morais equivale à necessidade de relatar as novidades introduzidas pelas chamadas, no livro do último dos escritores mencionados, obras literartísticas. Esses livros configuram-se, a priori, com uma alta densidade de uso imagético por um lado; por outro, ambos são textos cercados por outros meios e modos outros de fazer a literatura e as obras visuais. No caso do livro de Fábio Morais, ele também soa como uma recuperação do poder integrador das artes e do conhecimento humano por meio da palavra e de seu caráter pictográfico.

A integração de literatura e de sua contraparte imagética é quase uma recuperação utópica de como a humanidade constituiu o conhecimento pelas letras como a sua fonte primordial. Dito de outro modo, uma recuperação das aptidões da palavra como ilustração tal como a alfabetização pela linguagem imagética. No nosso tempo histórico, a relação entre palavra e imagem em obras da contemporaneidade parece dar vazão ao auge do uso dessa última em nossas sociedades. Portanto, a estética de obras como Site specific, um romance parece assentada no impulsionamento de imagens crepitantes no dia a dia de cada um/a, produzidas objetivamente, mas que, habilmente, encontram o sujeito à/ao qual pretende atingir.

No prefácio do artigo de Rosalind Krauss, Buchloch poderia ter ressaltado as obras de Broodthaers com as mesmas palavras do editor de Site Specific, um Romance, "[...] todo radicalismo co- 
Se você viajar pelo mar do Norte, um artigo, sobre Site Specific, um Romance Renan Augusto Ferreira Bolognin

meça cruel, incisivo, explosivo, para ir se adequando aos poucos, ir assentando a poeira até ter a quietude e a paz da tradição e do descanso" (MORAIS, 2013, p. 115). Tendo em vista as mudanças capciosas vivenciadas pelas inúmeras sociedades do globo, bem como as tecnologias e experimentações estéticas dos anos 1960 até a data corrente, o livro de Fábio Morais talvez não constranja como a obra de Broodthaers; embora elas sejam outras, entre tantas, daquelas sobre a qual muitos se perguntaram: "Isto é literatura?" ou "Isto é arte?". No entanto, seria impraticável deixar de ressaltar como a obra analisada neste artigo se situa no lugar central da questão problemática (para sempre irresoluta) da essência das formas artísticas e de seu lugar de exposição (como se refere ironicamente o título site specific tanto à obra de arte plástica contemporânea não transportável modificando o espaço físico, quanto a um lugar outro que essa obra pode ocupar, o livro, e como este suporte também ressignifica o campo literário e seu modo de leitura). Dessa maneira, essa forma outra, imagética, de ler esses textos e/ou profusão de imagens contidas no livro de Fábio Morais, além de demonstrar e, possivelmente, antecipar como os conteúdos verbais são e serão paulatinamente mais consumidos diariamente, também aponta os caminhos para onde avançarão as artes plásticas e literárias cada vez mais interligadas a sua porção imagética e que ambas, talvez, convergirão ainda mais.

\section{Referências}

BOURDIEU, Pierre. Algumas propriedades dos campos. In: BOURDIEU, Pierre. Questões de sociologia. Rio de Janeiro: Marco Zero, 1983. p. 89-94.

BOURDIEU, Pierre. O campo intelectual: um mundo à parte. In: BOURDIEU, Pierre. Coisas ditas. São Paulo: Brasiliense, 2004a. p. 169-180.

BROODTHAERS, Marcel. A Voyage on the North Sea. Impressão offset sobre papel, 15,3 x 18,2 cm. Colección MACBA. Fundación MACBA, Barcelona, 1973. Disponível em: https://www.macba.cat/es/arte-artis- 
Se você viajar pelo mar do Norte, um artigo, sobre Site Specific, um Romance Renan Augusto Ferreira Bolognin

tas/artistas/broodthaers-marcel/voyage-north-sea. Acesso em: 22 mar. 2021.

BUARQUE, Chico. O irmão alemão. São Paulo: Companhia das Letras, 2014.

CALVINO, Ítalo. Visibilidade. In: CALVINO, Ítalo. Seis propostas para o novo milênio: lições americanas. 3ed. São Paulo: Companhia das Letras, 1990. p. 95-114.

CANCLINI, Néstor García. A sociedade sem relato. Trad. Maria Paula Gurgel Ribeiro. SP: Edusp, 2016.

CONTINENTINO, Ana Maria Amado. A lógica dos indecidíveis. In: CONTINENTINO, Ana Maria Amado. A alteridade no pensamento de Jacques Derrida: Escritura, Meio-Luto, Aporia. Tese (Doutorado em Filosofia) - Pontifícia Universidade Católica do Rio de Janeiro, Rio de Janeiro, 2006. p. 16-18. Disponível em: https://www.maxwell.vrac.puc-rio.br/9591/9591_3.PDF. Acesso em: 24 set. 2020.

DERRIDA, Jacques. La doble sesión. In: DERRIDA, Jacques. La diseminación. 7ed. Trad. José Martin Arancibia. Madrid, España: Omagraf, 1997 (1972). p. 263-340.

DYLAN, Bob. Girl from the North Country. In: DYLAN, Bob. The freeweelin' Bob Dylan. Nova lorque: Sony, 1963, Spotify.

ELTIT, Diamela; ERRÁZURIZ, Paz. El infarto del alma. 2ed. Santiago de Chile: Francisco Zegers Editor, 1999.

ESQUIVEL, Laura. Como água para chocolate. Trad. Olga Savary. São Paulo: Martins Fontes, 1993.

GARRAMUÑO, Florencia. Frutos estranhos: sobre a inespecificidade na estética contemporânea. Trad. Carlos Nougué. Rio de Janeiro: Rocco, 2014.

HISSA, Cassio Eduardo Viana. Entrenotas: compreensões de pesquisa. Belo Horizonte: Ed. UFMG, 2013.

KIFFER, Ana; GARRAMUÑO, Florencia. Expansões contemporâneas: Literatura e outras formas. Belo Horizonte: UFMG, 2014. 
Se você viajar pelo mar do Norte, um artigo, sobre Site Specific, um Romance Renan Augusto Ferreira Bolognin

KRAUSS, Rosalind. A escultura no campo ampliado. Gávea, Trad. Elisabeth Carbone Baez, n.1, s/v, p. 129-137, 1984. Disponível em: http://monoskop.org/images/b/bc/Krauss_Rosalind_1979_2008_A_escultura_no_campo_ampliado.pdf. Acesso em: 14 jan. 2016.

KRAUSS, Rosalind. Sculpture in the expanded field. October, v.8, n. 120, p. 30-44, 1979. Disponível em: http://www.onedaysculpture.org.nz/assets/images/reading/Krauss.pdf. Acesso em: 22 out. 2015.

KRAUSS, Rosalind. Voyage on the North Sea: art in the age of the post-medium condition. Nova lorque: Thames \& Hudson, 1999.

LUDMER, Josefina. Literaturas pós-autônomas. Ciberletras, s/v, n. 17, p. 1-6, jul. 2007. Disponível em: http://www.culturaebarbarie.org/sopro/ n20.pdf. Acesso em: 08 jun. 2020.

MORAIS, Fábio. Site specific, um romance. Florianópolis: Par(ênt)esis, 2013.

MORETTI, Franco (Org.). A cultura do romance. Trad. Denise Bottmann. São Paulo: Cosac Naify, 2009. p. 629-658.

RODRIGUES, Emira. Malencuentro: pero tenía otros nombres. Caracas, Venezuela: el perro y la lana, 2008.

SUSSEKIND, Flora. Objetos verbais não identificados: um ensaio de Flora Sussekind. 0 globo, 21 set. 2013. Disponível em: https://iedamagri.files.wordpress.com/2015/04/objetos-verbais-nc3a3o-identificados-um-ensaio-de-flora-sc3bcssekind-prosa-o-globo.pdf. Acesso em: 16 jun. 2020.

VASCONCELOS, Sandra Guardini Teixeira. O romance como gênero planetário: a cultura do romance. Novos Estudos, Cebrap, s/v, n. 86, p. 87-95, 2010. Disponível em: http://www.scielo.br/pdf/nec/n86/n86a11.pdf. Acesso em: 16 jun. 2017. 